\title{
The survival outcome and complication of secondary cytoreductive surgery plus chemotherapy in recurrent ovarian cancer: a systematic review and meta-analysis
}

Ting Ding ${ }^{1}$, Dan Tang ${ }^{1}$ and Mingrong $\mathrm{Xi}^{2^{*}}$

\begin{abstract}
Objective: The aim of this meta-analysis was to assess the effectiveness and safety of secondary cytoreductive surgery plus chemotherapy (SCS + CT) in recurrent ovarian cancer (ROC). Our secondary purpose was to analyze whether patients could benefit from complete resection.
\end{abstract}

Methods: We searched EMBASE, MEDLINE, the Cochrane Database of Systematic Reviews and Cochrane Central Register of Controlled Trials, from inception to April 2021. We used appropriate scales to assess the risk of bias. Data from included studies that reported median PFS or OS were weighted by individual study sample size, and aggregated for meta-analysis. We calculated the pooled proportion of complications within 30 days after surgery.

Results: We identified 13 articles, including three RCTs and ten retrospective cohort studies. A total of 4572 patients were included, of which 916 patients achieved complete resection, and all patients were comparable at baseline. Compared with chemotherapy alone, SCS + CT significantly improved the PFS (HR=0.54, 95\% Cl: $0.43-0.67)$ and OS $(H R=0.60,95 \%$ Cl: $0.44-0.81)$. Contrary to the results of cohort studies, the meta-analysis of RCTs showed that SCS + CT could not bring OS benefits ( $\mathrm{HR}=0.93,95 \% \mathrm{Cl}: 0.66-1.3)$. The subgroup analysis showed the prognostic importance of complete resection. Compared with chemotherapy alone, complete resection was associated with longer PFS $(\mathrm{HR}=0.53,95 \% \mathrm{Cl}: 0.45-0.61)$ and $\mathrm{OS}(\mathrm{HR}=0.56,95 \% \mathrm{Cl}: 0.39-0.81)$, while incomplete resection had no survival benefit. Additionally, complete resection could maximize survival benefit compared with incomplete resection $(H R=0.56$, $95 \% \mathrm{Cl}: 0.46-0.69 ; \mathrm{HR}=0.61,95 \% \mathrm{Cl}: 0.50-0.75$ ). The pooled proportion for complications at 30 days was $21 \%$ (95\% Cl: $0.12-0.30$ ), and there was no statistical difference in chemotherapy toxicity between the two groups.

Conclusion: The review indicated that SCS +CT based regimens was correlated with better clinical prognosis for patients with recurrent ovarian cancer, but the interpretation of OS should be cautious. The meta-analysis emphasizes the importance of complete resection, suggesting that the potential benefits of prolonging survival may outweigh the disadvantages of any short-term complications associated with surgery.

\footnotetext{
*Correspondence: xmrjzz@126.com

2 Department of Obstetrics and Gynecology, West China Second

University Hospital, Key Laboratory of Birth Defects and Related Diseases of Women and Children, Sichuan University, Ministry of Education,

Number 20, 3rd Section, South Renmin Road, Chengdu 610041, Sichuan Province, China

Full list of author information is available at the end of the article
} permits use, sharing, adaptation, distribution and reproduction in any medium or format, as long as you give appropriate credit to the original author(s) and the source, provide a link to the Creative Commons licence, and indicate if changes were made. The images or other third party material in this article are included in the article's Creative Commons licence, unless indicated otherwise in a credit line to the material. If material is not included in the article's Creative Commons licence and your intended use is not permitted by statutory regulation or exceeds the permitted use, you will need to obtain permission directly from the copyright holder. To view a copy of this licence, visit http://creativecommons.org/licenses/by/4.0/. The Creative Commons Public Domain Dedication waiver (http://creativeco mmons.org/publicdomain/zero/1.0/) applies to the data made available in this article, unless otherwise stated in a credit line to the data. 
Keywords: Ovarian cancer, Secondary cytoreductive surgery, Meta-analysis, Systematic review

\section{Highlights}

- There is significant heterogeneity in literature with the use of SCS + CT in recurrent ovarian cancer, and one prospective evidence discourages SCS $+\mathrm{CT}$.

- The meta-analysis based on the latest evidence of randomized controlled trials and other related publications.

- Compared with chemotherapy alone, SCS + CT is associated with longer PFS, but the interpretation of OS should be cautious.

- Complete resection is shown to maximize survival benefit compared with incomplete resection and chemotherapy alone.

- The incidence of complications was low within 30 days after receiving surgery and there was no statistical difference in chemotherapy toxicity between the two groups.

\section{Introduction}

After first-line chemotherapy and targeted maintenance therapy, about $80 \%$ of patients with advanced ovarian cancer will relapse [1]. For patients with recurrent ovarian cancer (ROC), secondary cytoreductive surgery plus chemotherapy $(\mathrm{SCS}+\mathrm{CT})$ is a widely practiced option [2]. SCS is defined as surgery to further debulk the recurrent tumour after completing the main treatment and a certain period of remission [3]. However, the role of $\mathrm{SCS}+\mathrm{CT}$ in patients with ROC has not been defined by level-1 evidence. Among ROC patients, the difference in progression-free survival (PFS) and overall survival (OS) associated with SCS + CT compared with chemotherapy alone is still unclear.

In 2006, an exploratory study (DESKTOP I) identified factors associated with improved survival after SCS + CT, with data from 25 member institutions [4]. DESKTOP II applied three criteria (PS 0, complete resection at initial surgery, and ascites $<500 \mathrm{ml}$ ), naming them as "positive AGO-score" to prospectively select patients who might benefit from SCS + CT. In total, $76 \%$ of the patients with a positive AGO score achieved an optimal cytoreduction [5].

Subsequently, four randomized controlled trials (RCTs) were conducted to compare SCS + CT with chemotherapy alone in ROC patients: GOG-0213 (ClinicalTrials.gov number NCT00565851), DESKTOP III (ClinicalTrials. gov number NCT01166737), SOCceR (Netherlands Trial Register number NL3137) and SOC-1 (ClinicalTrials.gov number NCT01611766) [6]. The SOCceR trial was terminated early due to poor enrollment [7].

GOG-0213 trial randomized patients with ROC to SCS +CT or chemotherapy alone, and nearly $80 \%$ of patients in each group received bevacizumab [8]. In published data, there was no improvement in PFS and OS in surgery group, and even complete resection did not affect the prognosis of patients [9]. These findings changed the previous understanding of the significance of SCS $+\mathrm{CT}$ for platinum-sensitive ROC. The DESKTOP III trial enrolled a total of 407 patients who relapsed $\geq 6$ months after platinum chemotherapy with a positive AGO score [10]. The final analysis demonstrated that SCS + CT significantly improved the PFS and OS [11]. SOC-1 trial enrolled 357 patients with platinum-sensitive relapsed ovarian cancer with a platinum-free interval of at least 6 months after the end of first-line chemotherapy and were predicted to have potentially resectable disease according to the recurrence score (PET-CT imaging and iMODEL score) [12]. The results showed that SCS + CT was associated with longer PFS but not beneficial to OS.

One published meta-analysis suggested that SCS $+\mathrm{CT}$ significantly improved PFS for patients with ROC, but did not improve OS [13]. However, the study did not provide enough available data and did not assess the complications after surgery, making it difficult to fully estimate the clinical benefit of SCS + CT.

Given the conflicting evidence regarding the role of SCS $+\mathrm{CT}$, the study aimed to add additional data by including RCTs and a number of recent publications. The purpose of this meta-analysis was to evaluate the prognostic impact of SCS +CT on patients with ROC. Our secondary purpose was to analyze whether patients could benefit from complete resection. Considering the potential role of unmeasurable confounding factors in the selection of patients, we also performed a sensitivity analysis to determine the impact of unmeasurable confounding factors on our results.

\section{Method}

Data sources and searches

This analysis was reported in accordance with the Preferred Reporting Items for Systematic Reviews and Meta-Analyses (PRISMA) guidelines. The protocol was registered to the International Prospective Register of Systematic Review (PROSPERO) with registration number CRD42020209013. From 1946 to April 2021, the following databases were systematically searched: EMBASE, 
MEDLINE, the Cochrane Database of Systematic Reviews and Cochrane Central Register of Controlled Trials. We also searched abstracts of scientific meetings, registers of clinical trials (https://www.clinicaltrials.gov/) and reference lists of included studies. The search terms including "ovarian cancer", and "secondary cytoreductive surgery". Manually filter the citation list of the retrieved articles to ensure the sensitivity of the search strategy.

\section{Study selection}

Articles were accepted if they complied with the following eligibility criteria: 1) Clinical trials, cohort studies or case-control studies; 2) Patients with a diagnosis of recurrent ovarian cancer; 3) Comparison of secondary cytoreductive surgery plus chemotherapy and chemotherapy alone; 4) Median PFS, OS, the rate of complete resection and complications were reported; 5) Full-text publication; 6) English Publication. All titles identified by the search have been evaluated, and all potentially relevant publications have been fully searched. Two review authors (KG, TA) independently evaluated the eligibility of the papers and resolved their disagreements by discussion or by appeal to a third review author $(\mathrm{AB})$.

\section{Data extraction}

The following detailed information was extracted from the included studies according to pre-designed criteria: name of the first author, year of publication, journal, study design, study population, median or average age, intervention method, median OS, median PFS, complications and toxicity. We extracted the hazard ratio (HR) and 95\% confidence interval (CI) of PFS and OS for each article. The score of completeness of cytoreduction was evaluated according to Sugarbaker [14]. R0: complete resection (no residual disease); R1: the residual disease with nodules measuring less than $2.5 \mathrm{~mm}$; R2: the residual disease with nodules measuring between $2.5 \mathrm{~mm}$ and $2.5 \mathrm{~cm}$; R3: the residual nodules greater than $2.5 \mathrm{~cm}$. When possible, all the data extracted were relevant to an intention-to-treat (ITT) analysis. Two review authors (KG, TA) independently extracted the data into a data abstraction form specially designed for the review. When necessary, the reviewer resolved the differences of opinion by discussing or appealing to a third review author $(\mathrm{AB})$.

\section{Statistical analysis}

We used Review Manager 5.3 (http://www.cochrane.org) and Stata 15.0 software for statistical analysis. A $\chi^{2}$ heterogeneity test and sensitivity analysis were performed to assess the existence of statistical heterogeneity between studies. If the $\mathrm{I} 2>50 \%$, the random-effects model was applied, otherwise the fixed-effects model was adopted
[15]. The forest plots showed graphical representation of each study and pooled analysis. The weight provided by each study in the meta-analysis was reported graphically as a square of different size. The confidence interval (CI) was expressed as a horizontal line passing through the square for each study. The pooled HR was represented as a lozenge in the forest plot, and the size corresponded to the $95 \% \mathrm{CI}$ of the HR. A p value $\leq 0.05$ was considered significant.

\section{Risk of bias assessment}

We assessed the methodological quality in cohort studies using the Newcastle Ottawa Scale (NOS) and Minors Scale. Studies were classified as low, moderate or high risk of bias based on its overall score. The Cochrane Collaboration's Risk of Bias Tool and Jadad Scale were used for randomized controlled trials. To investigate publication bias, we performed a funnel plot analysis.

\section{Results}

\section{Search results and Study quality}

The literature search identified 3325 articles and evaluated the eligibility of 37 articles. We excluded 24 studies, 17 articles had no control group [4, 16-31], three articles were conference abstracts, two articles did not meet the inclusion and exclusion criteria [32, 33], one article received radiotherapy in the control group [34], and one prospective trial terminated early due to poor enrollment [35].

Finally, 13 articles were identified, including three RCTs and ten retrospective cohort studies $[9,11,12,36-$ 45]. Nine of those 13 articles reported complications with 30 days after surgery and were eligible for quantitative synthesis. Three studies reported on the 30-day reoperation rate. The PRISMA flow chart summarizing the process of study selection is shown in Fig. 1.

In total, the number of patients included in the metaanalysis was 4572, ranging from 52 to 964 patients per study. Of the 4572 patients, 1446 (31.6\%) received SCS + CT and $3126(68.4 \%)$ received chemotherapy alone. All articles were published between 2005 and 2021, with patients included from 1985 to 2019 (Table 1).

This study analyzed whether the included patients were comparable at baseline (Additional file 1: Table S1). Eastern Cooperative Oncology Group (ECOG) performance status (PS) was reported in four studies, and there was no significant difference in PS 0 between the two groups $(65.9 \%$ versus $68.7 \%$; $\mathrm{P}=0.32$ ) (Additional file 1: Figure S1). The initial diagnosis of FIGO staging was reported in ten studies, and there was a significant difference between the two groups $(\mathrm{P}=0.0001) .686(71.8 \%)$ patients in the SCS + CT group had stage III or IV disease compared to 2158 


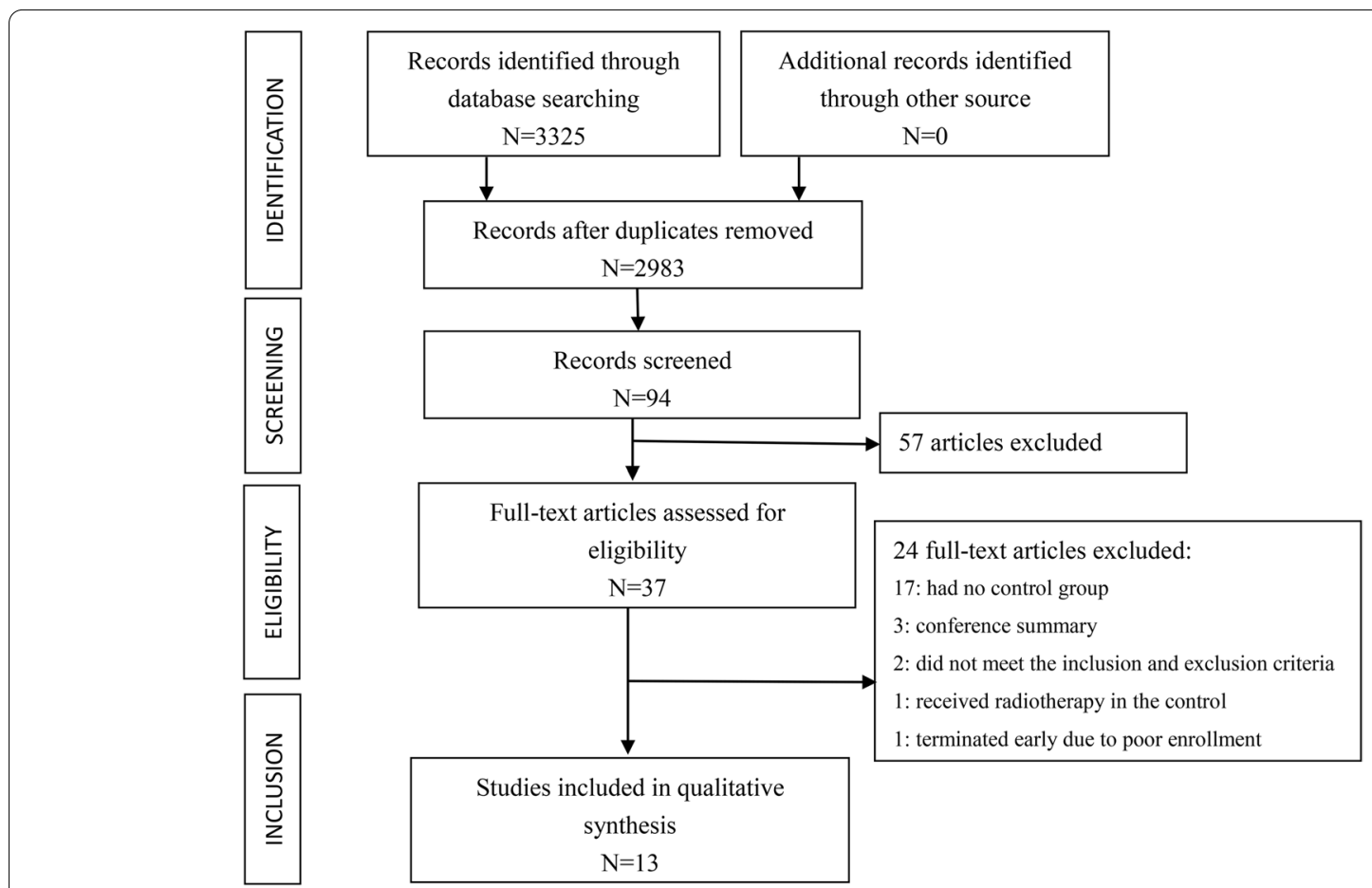

Fig. 1 Flow diagram of study selection for systematic review

(81.5\%) patients in the chemotherapy group. Tumor histology was reported in eight studies, of which 1790 (77\%) patients had high grade serous carcinoma, and there was no statistical difference between the two groups $(77.4 \%$ versus $76.7 \% ; \mathrm{P}=0.43)$. Four studies reported the presence or absence of ascites at the time of relapse, and there was no statistical difference between the two groups $(87.1 \%$ versus $70.5 \%$; $\mathrm{P}=0.44)$. Residual disease after initial operation was reported in five articles, and there was no statistical difference between the two groups (53.6\% versus 52.9\%; $\mathrm{P}=0.24$ ). Seven articles reported the number of recurrent lesions by imaging. The number of recurrent lesions in the chemotherapy group was significantly higher than that in the surgery group $(49.2 \%$ versus $23.4 \%$; $\mathrm{P}<0.0001)$. Five articles reported the site of recurrent lesions, and there was no statistical difference between intra-abdominal lesions and extra-abdominal lesions (82.6\% versus $89.3 \%$; $\mathrm{P}=0.48$ ).

Included patients in each study were divided into experiment group (SCS $+\mathrm{CT}$ ) and control group (CT), and the control group received platinum-based chemotherapy. The chemotherapy regimen used in each study was the standard treatment regimen during the study period. None of the included studies used high temperature intraperitoneal chemotherapy (HIPEC).

\section{Secondary cytoreductive surgery plus chemotherapy vs. Chemotherapy alone}

All included studies compared the efficacy of SCS + CT and chemotherapy alone in ROC patients. Four cohort studies did not report standard errors or $95 \%$ confidence intervals of log HR, only the significance probabilities of significant variables in the Cox model were reported. Nine studies were eligible to assess the impact of SCS + CT on OS, and eight studies provided available data to calculate the HR of the PFS. Pooled data demonstrated that compared with chemotherapy alone, the SCS + CT significantly improved the PFS $(\mathrm{HR}=0.54$, 95\% CI: $0.43-0.67, \mathrm{P}<0.00001)$ and $\mathrm{OS}(\mathrm{HR}=0.60,95 \%$ CI: 0.44-0.81, $\mathrm{P}=0.0007$ ) (Fig. 2).

Due to the contradictions between the results of RCTs, we conducted a subgroup analysis (Additional file 1: Figure S2). The subgroup analysis indicated that SCS + CT did not improve OS (I2 $=75 \%$; HR $=0.93$, 95\% CI: $0.66-$ 1.31, $\mathrm{P}=0.69)$, which was contrary to the results of cohort studies $(\mathrm{I} 2=0 \%$; $\mathrm{HR}=0.47,95 \% \mathrm{CI}$ : $0.40-0.55$, $\mathrm{P}<0.00001$ ).

The heterogeneity test was conducted based on the HR and $95 \%$ CI of PFS $\left(\mathrm{I}^{2}=73 \%, \mathrm{P}=0.0005\right)$ and $\mathrm{OS}$ $\left(\mathrm{I}^{2}=82 \%, \mathrm{P}<0.001\right)$. The results showed that the nine studies were highly heterogeneous. To investigate the impact of the individual study on the pooled data, we 
Table 1 Characteristics of included studies

\begin{tabular}{|c|c|c|c|c|c|c|c|c|}
\hline Study & Year & Study type & $\begin{array}{l}\text { Total } \\
\mathrm{n}\end{array}$ & $\begin{array}{l}\text { HR of PFS } \\
(95 \% \mathrm{Cl})\end{array}$ & P value & $\begin{array}{l}\text { HR of OS } \\
(95 \% \mathrm{Cl})\end{array}$ & P value & Jadad Score \\
\hline $\begin{array}{l}\text { Coleman et al } \\
\text { [9] }\end{array}$ & 2019 & $\begin{array}{l}\text { RCT } \\
\text { (GOG-0213) }\end{array}$ & 485 & $0.82(0.66-1.01)$ & $P=0.073$ & $1.29(0.97-1.72)$ & $P>0.05$ & 5 \\
\hline $\begin{array}{l}\text { du Bois et al. }{ }^{a} \\
{[11]}\end{array}$ & 2020 & $\begin{array}{l}\text { RCT } \\
\text { (DESKTOP III) }\end{array}$ & 407 & $0.66(0.52-0.83)$ & $P<0.001$ & $0.76(0.59-0.97)$ & $P<0.05$ & 5 \\
\hline $\begin{array}{l}\text { Shi et al } \\
{[12]}\end{array}$ & 2021 & $\begin{array}{l}\text { RCT } \\
(\mathrm{SOC}-1)\end{array}$ & 357 & $0.58(0.45-0.74)$ & $P<0.001$ & $0.82(0.57-1.19)$ & $P=0.29$ & 5 \\
\hline Study & Year & Study type & $\begin{array}{l}\text { Total } \\
\mathrm{n}\end{array}$ & HR of PFS $(95 \% \mathrm{Cl})$ & P value & $\begin{array}{l}\text { HR of OS } \\
(95 \% \mathrm{Cl})\end{array}$ & $P$ value & Minors Score \\
\hline $\begin{array}{l}\text { Gockley et al } \\
\text { [36] }\end{array}$ & 2019 & Retrospective & 626 & $N R$ & NR & $0.45(0.32-0.65)$ & $P<0.001$ & 20 \\
\hline $\begin{array}{l}\text { Felsinger et al } \\
{[37]}\end{array}$ & 2018 & Retrospective & 62 & NR & $P=0.01$ & NR & $P=0.007$ & 18 \\
\hline $\begin{array}{l}\text { Szczesny et al } \\
\text { [38] }\end{array}$ & 2018 & Retrospective & 397 & $0.45(0.32-0.62)$ & $P<0.001$ & $0.5(0.32-0.70)$ & $P<0.001$ & 18 \\
\hline $\begin{array}{l}\text { Lee et al } \\
\text { [39] }\end{array}$ & 2015 & Retrospective & 964 & $0.42(0.33-0.52)$ & $P<0.001$ & $0.49(0.39-0.61)$ & $P<0.001$ & 20 \\
\hline $\begin{array}{l}\text { Ortega et al } \\
\text { [40] }\end{array}$ & 2020 & Retrospective & 71 & $0.28(0.15-0.5)$ & $p=0.001$ & $0.33(0.17-0.6)$ & $P=0.001$ & 20 \\
\hline $\begin{array}{l}\text { So M et al } \\
\text { [41] }\end{array}$ & 2019 & Retrospective & 52 & $0.45(0.22-0.91)$ & $P=0.027$ & $0.28(0.11-0.72)$ & $P=0.008$ & 20 \\
\hline $\begin{array}{l}\text { Güngör et al } \\
\text { [42] }\end{array}$ & 2005 & Retrospective & 75 & $N R$ & NR & NR & $P=0.03$ & 17 \\
\hline $\begin{array}{l}\text { Oksefjell et al } \\
\text { [43] }\end{array}$ & 2009 & Retrospective & 789 & NR & NR & NR & $P<0.01$ & 16 \\
\hline $\begin{array}{l}\text { Takahashi et al } \\
\text { [44] }\end{array}$ & 2017 & Retrospective & 112 & $0.57(0.33-0.97)$ & $P=0.02$ & $0.66(0.33-1.31)$ & $P=0.23$ & 19 \\
\hline $\begin{array}{l}\text { Kajiyama et al } \\
{[45]}\end{array}$ & 2019 & Retrospective & 169 & $N R$ & $P=0.114$ & NR & $P=0.32$ & 17 \\
\hline
\end{tabular}

The number, $\mathrm{HR}, 95 \% \mathrm{Cl}$ or $\mathrm{P}$ value is shown for $\mathrm{SCS}+\mathrm{CT}$ versus $\mathrm{CT}$. ${ }^{\mathrm{a}}$ study including latest data presented at $\mathrm{ASCO} 2020$

Abbreviations: $H R$ hazard ratio, $95 \% \mathrm{Cl} 95 \%$ confidence interval, PFS progression-free survival, OS overall survival, NR not reported

conducted a sensitivity analysis (Additional file 1: Figure S3). Every study was deleted consecutively to test the stability of the data. The result of PFS and OS was robust, sequential omission of data from any individual study did not affect the results.

\section{Subgroup analysis}

We conducted a subgroup analysis to assess the impact of complete resection on survival outcomes. All included articles reported the number of patients with complete resection (Table 2). Of the 1446 patients who received SCS + CT, 916 patients achieved complete resection.

Six studies were eligible to compare the effects of complete resection and chemotherapy alone, but one of them did not report the standard error or $95 \% \mathrm{CI}$ of $\log$ HR. The meta-analysis of five articles evaluated 1971 patients (complete resection group: 542, chemotherapy alone group: 1429). Pooled data demonstrated that compared with chemotherapy alone, complete resection significantly improved PFS (HR $=0.53,95 \%$ CI: $0.45-0.61$,
$\mathrm{P}<0.00001)$ and $\mathrm{OS}(\mathrm{HR}=0.56,95 \% \mathrm{CI}: 0.39-0.81$, $\mathrm{P}=0.002$ ) (Fig. 3).

In addition, two articles compared the efficacy of incomplete resection and chemotherapy alone, and evaluated 855 patients (incomplete resection group: 194; chemotherapy alone group: 661). The results indicated that compared with chemotherapy alone, incomplete resection did not improve $\mathrm{OS}(\mathrm{HR}=1.16,95 \%$ CI: $0.53-2.54, \mathrm{P}=0.71)$. Only the SOC-1 trial reported PFS, 12.6 months in the incomplete resection group and 11.9 months in the chemotherapy group ( $\mathrm{HR}=0.91,95 \%$ CI: 0.61-1.36).

In order to explore the impact of residual tumors on survival outcomes, we compared the effects of complete resection and incomplete resection on the prognosis of patients. Two articles were included in the meta-analysis, and evaluated 427 patients (complete resection group: 290; incomplete resection group: 137).The results showed that complete resection were associated with longer PFS (HR $=0.56,95 \% \mathrm{CI}: 0.46-0.69, \mathrm{P}<0.00001)$ and $\mathrm{OS}$ $(\mathrm{HR}=0.61,95 \% \mathrm{CI}: 0.50-0.75, \mathrm{P}<0.00001)$. 


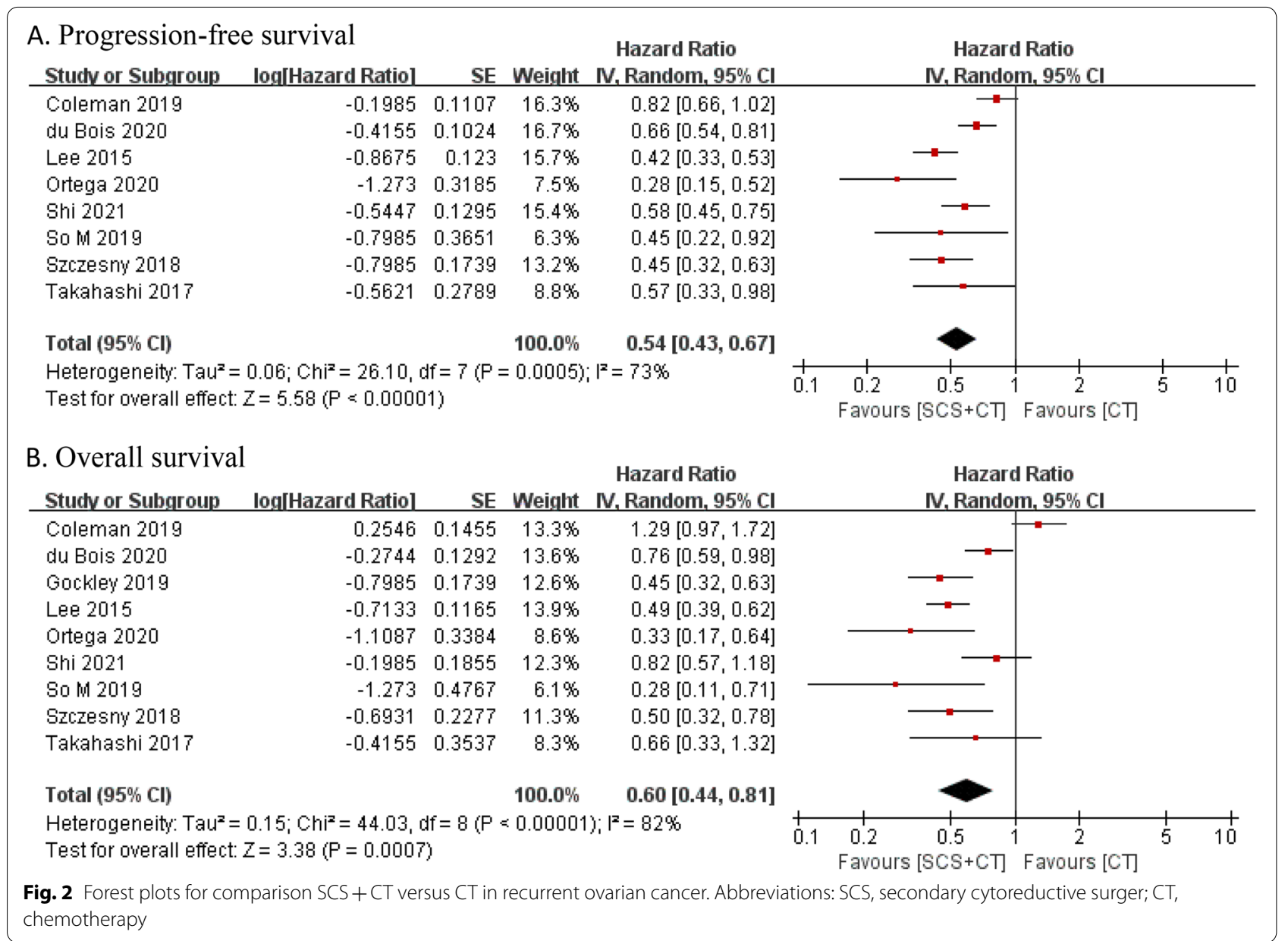

The results of heterogeneity test showed that the six articles were highly heterogeneous (R0 vs. CT: I $2=77 \%$, $\mathrm{P}=0.001 ; \mathrm{R} 1+\mathrm{R} 2+\mathrm{R} 3$ vs. $\mathrm{CT}: \mathrm{I} 2=87 \%, \mathrm{P}=0.006)$. Sensitivity analysis indicated that the result of PFS and OS was reliable, and sequential omission of data from any individual study did not affect the results (Additional file 1: Figure S4).

\section{Complications and toxicity}

Nine articles reported that 347 patients underwent bowel resection, and two articles reported that 193 patients suffered haemorrhage or required blood transfusion during surgery (Additional File 1: Table S2). Nine articles reported the incidence of complications about intraoperative or postoperative. 191 (20.1\%) of 953 patients had complications within 30 days after SCS, and the pooled proportion among patients was $21 \%$ (95\% CI: 0.12-0.30) (Fig. 4). 8 (4.1\%) patients had pleural effusion, $86(45.0 \%)$ patients had intestinal obstruction, 7 (3.7\%) patients had deep vein thrombosis, and 25 (13.1\%) patients had repeated operations. In addition, 27 (14.1\%) patients developed postoperative infections, including wound infections, abdominal infections, lung infections and urinary tract infections. 4 (2.1\%) patients developed heart events, and 34 (17.9\%) patients had other complications (bleeding, intestinal fistula and renal impairment). Most patients had grade 1-2 complications, and only the GOG-0213 trial reported one patient died within 30 days after surgery due to pulmonary embolism [9].

Only two articles (SOC-1 and GOG-0213 trial) reported the toxicity of chemotherapy, and there was no statistical difference between the two groups $(\mathrm{P}=0.90)$ [9, 12]. In SOC-1 trial, 41 (23\%) of 182 patients in the SCS + CT group and 31 (18\%) of 175 in the chemotherapy group had grade 3 or worse adverse events during chemotherapy $(P>0.2)$. The most common grade 3-4 adverse events during chemotherapy were neutropenia (SCS + CT group: 29; CT group: 19), leucopenia (SCS + CT group: 14; CT group: 8), and anaemia (SCS + CT group: 10; CT group: 9) $(\mathrm{P}>0.5)$. Two patients in the SCS $+\mathrm{CT}$ group discontinued treatment due to chemotherapy-related toxicity. In GOG-0213 trial, 183 
Table 2 Characteristics of patients with complete resection included in the study

\begin{tabular}{|c|c|c|c|c|c|c|c|c|c|}
\hline \multirow[t]{2}{*}{ Author } & \multirow{2}{*}{$\begin{array}{l}\text { SCS } \\
\mathrm{n}\end{array}$} & \multirow{2}{*}{$\begin{array}{l}\mathrm{CT} \\
\mathrm{n}\end{array}$} & \multirow{2}{*}{$\begin{array}{l}\text { Ro } \\
\text { n }\end{array}$} & \multicolumn{2}{|c|}{ R0 vs. R1 + R2 + R3 } & \multicolumn{2}{|l|}{ Ro vs. CT } & \multicolumn{2}{|c|}{$\mathrm{R} 1+\mathrm{R} 2+\mathrm{R} 3$ vs. CT } \\
\hline & & & & PFS & os & PFS & os & PFS & os \\
\hline $\begin{array}{l}\text { Coleman et al } \\
\text { [9] }\end{array}$ & 240 & 245 & 150 & $0.51(0.36-0.71)$ & $0.61(0.40-0.93)$ & $0.62(0.48-0.80)$ & $1.03(0.74-1.46)$ & $N R$ & $N R$ \\
\hline $\begin{array}{l}\text { du Bois et al } \\
{[11]}\end{array}$ & 206 & 201 & 138 & $N R$ & $N R$ & $0.56(0.43-0.73)$ & $0.57(0.43-0.76)$ & $N R$ & NR \\
\hline $\begin{array}{l}\text { Shi et al } \\
{[12]}\end{array}$ & 182 & 175 & 132 & $N R$ & $N R$ & $0.5(0.37-0.66)$ & $0.59(0.38-0.91)$ & $0.91(0.61-1.36)$ & $1.79(1.07-2.99)$ \\
\hline $\begin{array}{l}\text { Gockley et al } \\
{[36]}\end{array}$ & 146 & 480 & 62 & $N R$ & $N R$ & $N R$ & $0.38(0.23-0.64)$ & NR & $0.8(0.62-1.03)$ \\
\hline $\begin{array}{l}\text { Felsinger et al } \\
\text { [37] }\end{array}$ & 30 & 32 & 24 & $N R$ & $N R$ & $N R$ & $N R$ & $N R$ & $N R$ \\
\hline $\begin{array}{l}\text { Szczesny et al } \\
\text { [38] }\end{array}$ & 75 & 322 & 60 & $N R$ & $N R$ & $0.34(0.23-0.51)$ & $0.36(0.22-0.57)$ & $N R$ & $N R$ \\
\hline $\begin{array}{l}\text { Lee et al } \\
\text { [39] }\end{array}$ & 187 & 777 & 140 & $0.59(0.46-0.76)$ & $0.61(0.48-0.79)$ & $N R$ & $N R$ & $N R$ & NR \\
\hline $\begin{array}{l}\text { Ortega et al } \\
{[40]}\end{array}$ & 37 & 34 & 33 & $N R$ & $N R$ & $N R$ & $N R$ & $N R$ & $N R$ \\
\hline $\begin{array}{l}\text { So M et al } \\
\text { [41] }\end{array}$ & 22 & 30 & 16 & $N R$ & $N R$ & $N R$ & $N R$ & NR & NR \\
\hline $\begin{array}{l}\text { Güngör et al } \\
\text { [42] }\end{array}$ & 44 & 31 & 34 & $N R$ & NR & NR & $N R$ & $N R$ & $N R$ \\
\hline $\begin{array}{l}\text { Oksefjell et al } \\
\text { [43] }\end{array}$ & 217 & 572 & 76 & $N R$ & NR & $N R$ & $N R$ & NR & NR \\
\hline $\begin{array}{l}\text { Takahashi et al } \\
\text { [44] }\end{array}$ & 35 & 77 & 33 & $N R$ & $N R$ & $N R$ & $N R$ & $N R$ & $N R$ \\
\hline $\begin{array}{l}\text { Kajiyama et al } \\
{[45]}\end{array}$ & 25 & 144 & 18 & $N R$ & $N R$ & $N R$ & $N R$ & $N R$ & $N R$ \\
\hline
\end{tabular}

Abbreviations: SCS secondary cytoreductive surgery, $C T$ chemotherapy, $R 0$ complete resection (the presence of zero macroscopic residuum), $R 1+R 2+R 3$ incomplete resection, PFS progression-free survival, OS overall survival, NR not reported

(76.3\%) of 240 patients in the SCS + CT group and 194 (79.2\%) of 245 in the chemotherapy group had grade 3 or worse adverse events during chemotherapy $(\mathrm{P}=0.44)$. Two patients in the chemotherapy group died due to cardiac events.

\section{Risk of bias in included studies}

We assessed all full-text studies for methodological quality (Additional file 1: Appendix 2-3-4-5). In all included studies, appropriate statistical techniques were used to analyze PFS and OS, and multivariate analysis was used to adjust for important prognostic factors in the Cox regression model, making the two groups comparable. In addition, all included studies appeared to include a representative sample of patients with ROC that had been cytoreduced via SCS. We included only sufficiently large studies and used multivariate analysis to control various co-factors to reduce the possibility of selection bias. Considering the fact that the comparison of residual diseases almost came from cohort studies, we should be cautious when conducting data extraction and meta-analysis. In short, although cohort studies had a high risk of bias, each study was representative and comparable.
Begg's test and Egger's test were applied to evaluate the bias of publication, and there was no significant bias in PFS $(\mathrm{PB}=0.266, \mathrm{PE}=0.226)$ and $\mathrm{OS}(\mathrm{PB}=0.754$, $\mathrm{PE}=0.433)$ (Additional file 1: Figure S5).

\section{Discussion}

Whether SCS + CT can improve the prognosis of ROC and whether patients can benefit from complete resection are still clinically controversial issues. Almost all retrospective studies indicated that SCS + CT was beneficial to patients with ROC, especially those who had achieved complete resection. However, the results of RCTs in the past 10 years were contrary to this, and the results of several RCT trials were contradictory $[9,11,12]$. The results of GOG-0213 trial showed that there was no significant difference of PFS (18.9 vs. 16.2 months; $\mathrm{P}=0.073$ ) and $\mathrm{OS}$ (50.6 vs. 64.7 months; $\mathrm{P}=0.08$ ) between the SCS $+\mathrm{CT}$ group and the chemotherapy group [9]. Even if complete resection was achieved, it did not affect the prognosis of the patient (56.0 vs.64.7 months; $\mathrm{P}>0.05)$. Primary endpoint analysis of DESKTOP III trial showed that median OS of 53.7 months with and 46.2 months without surgery $(\mathrm{P}=0.03)$; median PFS was 18.4 and 14 months $(\mathrm{P}<0.001)$ 


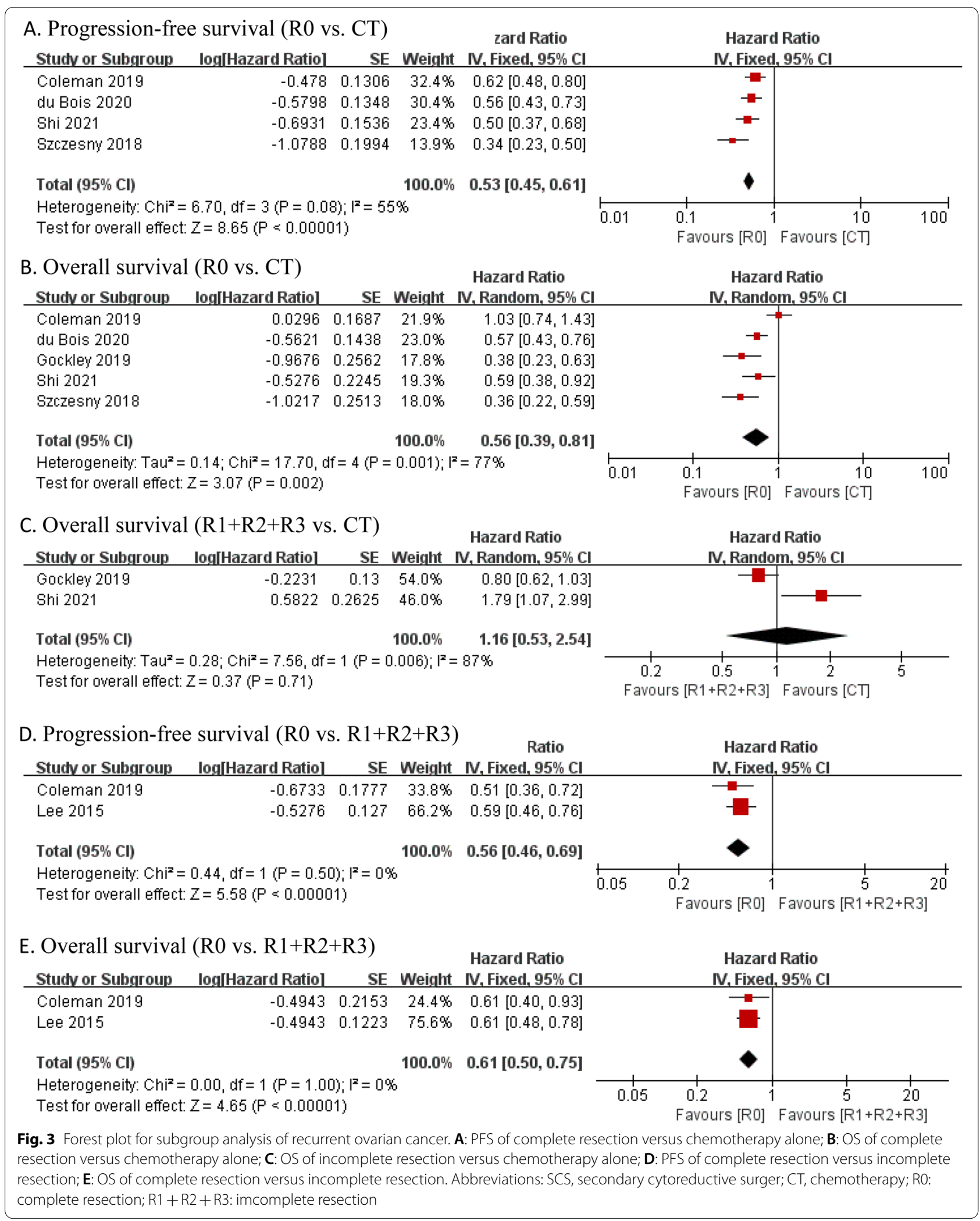




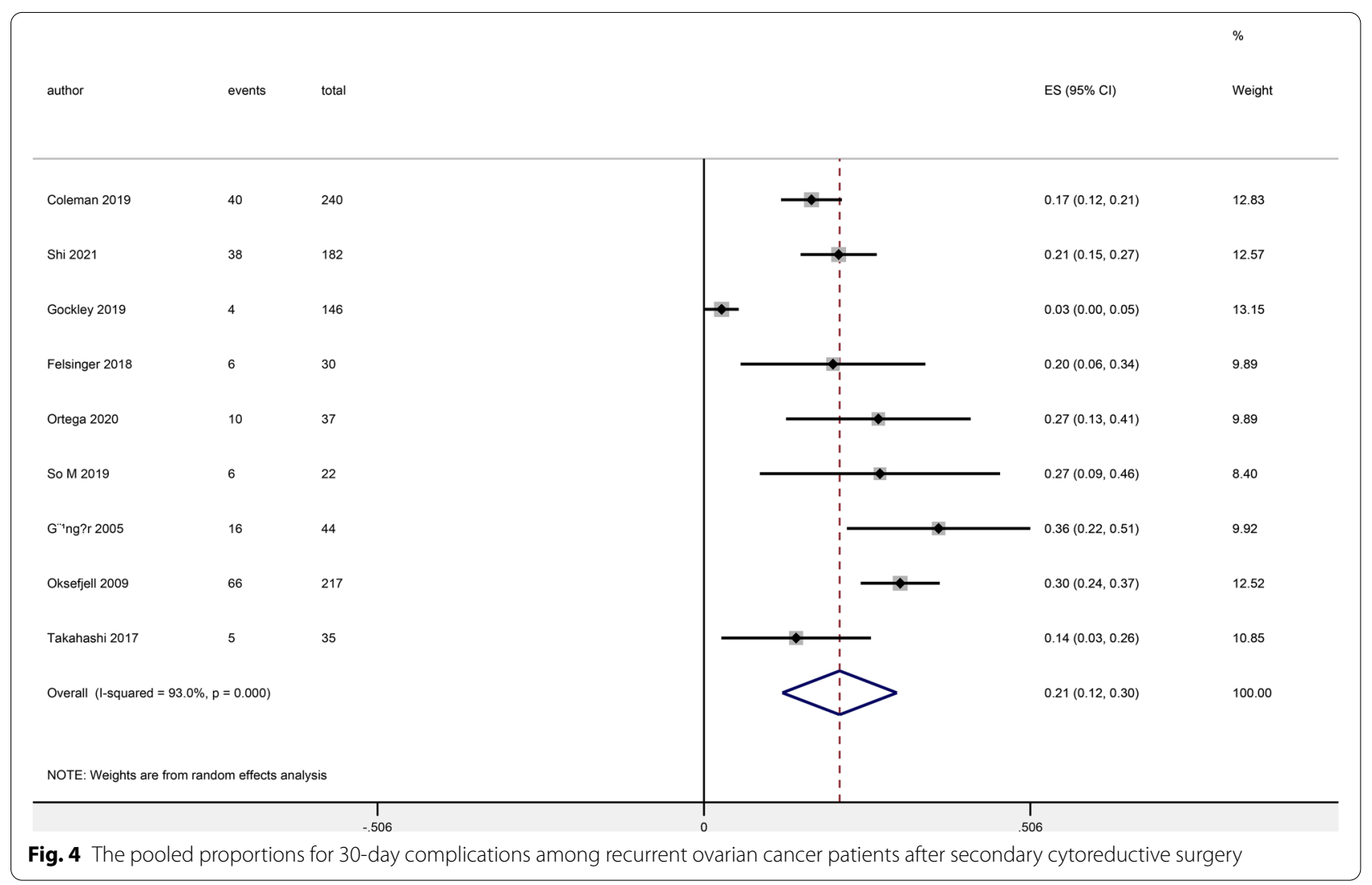

[11]. In SOC-1 trial, the PFS of SCS +CT group and chemotherapy group was 17.4 months and 11.9 months, respectively $(\mathrm{P}<0.0001)$, and the OS was 58.1 months and 53.9 months, respectively $(\mathrm{P}>0.05)$ [12].

In this meta-analysis, three RCTs and ten cohort studies were included. Pooled data demonstrated that SCS + CT significantly improved the PFS $(\mathrm{P}<0.0001)$ and $O S(P=0.02)$ in patients with ROC. Subgroup analysis of RCTs indicated that SCS + CT had no effect on OS $(P=0.67)$, which was contrary to the results of cohort studies $(\mathrm{P}<0.0001)$.

In order to explain the contradictions between the research results, several key points need to be further discussed. First, adjuvant therapy might affect the efficacy of surgery. The GOG-0213 trial is designed to assess two clinically relevant hypotheses: that bevacizumab plus chemotherapy improves OS (chemotherapy objective) and that secondary surgical cytoreduction in ROC patients improves OS (surgical objective). Nearly $80 \%$ of patients in each group received bevacizumab [8]. The median OS was nearly three times longer than expected when the trial was designed. In addition to considering the improvement of clinical care, the selection of bevacizumab may have masked an incremental benefit from surgery. However, the subgroup analysis showed that there was no difference between the surgery group and chemotherapy group in patients receiving bevacizumab (58.5 months vs. 61.7 months; $\mathrm{HR}=0.95$; $95 \% \mathrm{CI}$ : $0.65-1.38$ ). The OS of patients without bevacizumab was 32.4 months in the surgery group and 67.0 months in the chemotherapy group, respectively $(\mathrm{HR}=2.3,95 \% \mathrm{CI}$ : 1.29-4.10). These findings indicated that patients with ROC in the surgery group rather than in the chemotherapy group benefited from bevacizumab. Therefore, the use of bevacizumab might not be the main reason for the difference in PFS and OS estimate between GOG-0213 and the other two trials. Prospective RCTs of surgery combined with bevacizumab will help to answer this question. The results of GOG-0213 should be carefully considered, and chemotherapy alone should not be blindly recommended for all patients to replace $\mathrm{SCS}+\mathrm{CT}$.

Second, the criteria for patient selection were different among included studies. Only the SO M 2019 study used the "Tian" model to enroll patients, while the other cohort studies did not use uniform inclusion standard [41]. In GOG-0213 trial, patients were selected on the basis of investigator discretion, without using of objective tools [9]. The DESKTOP-III trial selected patients using the criteria algorithm (AGO score), based on a PS of 0 
on the ECOG score, complete resection at primary surgery and ascites of less than $500 \mathrm{ml}$ [11]. The SOC-1 trial selected patients using the iMODEL plus PET-CT scoring algorithm. iMODEL score combined with PET-CT selected more potential candidates than the AGO score [12]. $68 \%$ of patients in the DESKTOP-III trial achieved complete resection, similar to the GOG-0213 trial (67\%), while $77 \%$ of patients in SOC-1 trial achieved complete resection. Therefore, different criteria for patient selection and different maturity of trials may have an impact on the value of surgery.

Finally, the subgroup analysis of RCTs showed that $\mathrm{SCS}+\mathrm{CT}$ could not bring OS benefit, which was contrary to the results of cohort studies. Cohort study is a retrospective analysis of previous data with a risk of bias, especially selection bias and result reporting bias. Although most included retrospective studies used a propensity scorematched cohort and appropriate statistical techniques to analyze OS, the interpretation of the results should be cautious. More prospective RCTs are still needed to demonstrate whether SCS +CT can bring OS benefits.

In addition, we compared complete resection with chemotherapy alone. Meta-analysis and individual studies clearly showed that complete resection was associated with longer PFS $(\mathrm{P}<0.0001)$ and OS $(\mathrm{P}=0.002)$, and patients who achieved complete resection could benefit from surgery. The DSKTOP III trial reported that the median OS of complete resection was 60.7 months, which was more than 12 months better than the chemotherapy alone group, suggesting that only complete resection could bring OS benefits. Only two studies compared the incomplete resection with chemotherapy alone [12, 36]. The meta-analysis showed that patients with incomplete resection had no significant $\mathrm{OS}$ benefit $(\mathrm{HR}=1.16$, 95\% CI: 0.53-2.54, $\mathrm{P}=0.71$ ).

Moreover, we compared the effects of complete resection and incomplete resection on survival outcomes. The results of this study showed that complete resection improved PFS $(\mathrm{P}<0.001)$ and $\mathrm{OS}(\mathrm{P}<0.001)$. The subgroup analysis of the SOC-1 trial showed that PFS was 19.2 months in the complete resection group and 12.6 months in the incomplete resection group. The subgroup analysis of the DSKTOP III trial showed that the median OS of complete resection was 60.7 months, while the median OS of incomplete resection was only 28.8 months. These findings indicated that the degree of completion of the cell reduction was an important factor affecting the prognosis of patients. Although the metaanalysis included cohort studies, all studies included at least 50 women, and statistical adjustments were used for important prognostic factors. This fact improved the certainty of the estimates.
Only two articles reported chemotherapy toxicity, and there was no statistical difference between the two groups $(P>0.05)[9,12]$. Nine studies reported complications, and 191 of 953 patients had complications within 30 days after surgery. Most patients had grade 1-2 adverse reactions, and only one death related to surgery was reported [9]. Treatment-related adverse reactions usually degrade the quality of life of patients, which is especially important after completing treatment for recurrent cancer, where patients want to enjoy a comfortable standard of living because of the poor prognosis. None of the included articles had quality of life assessment as a component of the studies. Quality of life may be more important for women who have recurrent disease and have significant physical limitations to their life due to the development of the disease and the results of receiving treatment. In this study, the impact of treatment-related adverse events on the life of patients should be considered, which needs more research to confirm. In short, compared with chemotherapy alone, the survival outcome of patients undergoing SCS + CT was much better. In addition, the meta-analysis emphasizes the importance of complete resection for patients, suggesting that the potential benefits of prolonging survival may outweigh the disadvantages of any short-term morbidity associated with surgery.

\section{Conclusion}

In conclusion, SCS-based regimens might result in favorable PFS and OS for patients with ROC. Among patients underwent surgery, only complete resection could bring survival benefits. The incidence of chemotherapy-related toxicity and postoperative complications were low, and serious and fatal adverse reactions rarely occur.

\section{Abbreviations}

SCS: Secondary cytoreductive surgery; CT: Chemotherapy; ROC: Recurrent ovarian cancer; PFS: Progression-free survival; OS: Overall survival; HR: Hazard ratio; Cl: Confidence interval; ITT: Intention-to-treat; PS: Performance status.

\section{Supplementary Information}

The online version contains supplementary material available at https://doi. org/10.1186/s13048-021-00842-9.

Additional file 1: Appendix 1. Search strategies. Appendix 2. Risk of bias assessment results for cohort studies using the Newcastle Ottawa Scale. Appendix 3.Risk of bias assessment results for cohort studies using the Minors Scale. Appendix 4. Risk of bias assessment results for randomized studies using the Jadad Scale. Appendix 5. Risk of bias assessment results for randomized studies using Cochrane Risk of Bias Tool. Table S1. Baseline characteristics of included patients. Table S2. Complications and toxicity. Figure S1. Forest plot for included in the patient's baseline analysis. Figure S2. Forest plot for OS subgroup analysis of recurrent ovarian cancer. Figure S3. Sensitivity analysis of PFS and OS. Figure S4. Sensitivity analysis of OS. Figure S5. Begg's and Egger's test of PFS and OS. 


\section{Additional file 2 . \\ Additional file 3. \\ Additional file 4 \\ Additional file 5 \\ Additional file 6}

\section{Acknowledgements}

We would like to thank all authors who provided published data for our meta-analysis.

\section{Authors' contributions}

Ting Ding analyzed and interpreted the data and was the main contributor in writing the manuscript. Ting Ding, Dan Tang extract data and analyze it. Mingrong Xi revised it critically for important intellectual content. All authors approved the final manuscript.

\section{Funding}

This research did not receive any specific grant from funding agencies in the public, commercial, or not-for-profit sectors.

\section{Availability of data and materials}

All data is available in this paper.

\section{Declarations}

Ethics approval and consent to participate

Not applicable.

\section{Consent for publication}

Not applicable.

\section{Competing interests}

The authors declare that they have no competing interests.

\section{Author details}

'Department of Obstetrics and Gynecology, West China Second Hospital, Key Laboratory of Birth Defects and Related Diseases of Women and Children, Sichuan University, Ministry of Education, Number 20, 3rd Section, South Renmin Road, Chengdu 610041, Sichuan Province, China. ${ }^{2}$ Department of Obstetrics and Gynecology, West China Second University Hospital, Key Laboratory of Birth Defects and Related Diseases of Women and Children, Sichuan University, Ministry of Education, Number 20, 3rd Section, South Renmin Road, Chengdu 610041, Sichuan Province, China.

Received: 12 May 2021 Accepted: 29 June 2021

Published online: 13 July 2021

\section{References}

1. Luvero D, Plotti F, Aloisia A, Montera R, Terranova C, Carlo De Cicco Nardone, Scaletta G, Lopez S, Miranda A, Capriglione S, Gatti A, Pierluigi Benedetti Panici, Angioli R. Ovarian cancer relapse: From the latest scientific evidence to the best practice. Crit Rev Oncol Hematol. 2019;140:2838. https://doi.org/10.1016/j.critrevonc.2019.05.014. Epub 2019 May 29. PMID: 31176270.

2. Bommert M, Harter P, Heitz F, du Bois A. When should Surgery be used for Recurrent Ovarian Carcinoma? Clin Oncol (R Coll Radiol). 2018;30(8):4937. https://doi.org/10.1016/j.clon.2018.04.006 Epub 2018 May 7 PMID: 29743148.

3. Al Rawahi T, Lopes AD, Bristow RE, Bryant A, Elattar A, Chattopadhyay S, Galaal K. Surgical cytoreduction for recurrent epithelial ovarian cancer. Cochrane Database Syst Rev. 2013 Feb 28;2013(2):CD008765. https:// doi.org/10.1002/14651858.CD008765.pub3. PMID: 23450588; PMCID: PMC6457850.

4. Harter P, du Bois A, Hahmann M, Hasenburg A, Burges A, Loibl S, Gropp M, Huober J, Fink D, Schröder W, Muenstedt K, Schmalfeldt B, Emons G,
Pfisterer J, Wollschlaeger K, Meerpohl HG, Breitbach GP, Tanner B, Sehouli J; Arbeitsgemeinschaft Gynaekologische Onkologie Ovarian Committee; AGO Ovarian Cancer Study Group. Surgery in recurrent ovarian cancer: the Arbeitsgemeinschaft Gynaekologische Onkologie (AGO) DESKTOP OVAR trial. Ann Surg Oncol. 2006;13(12):1702-10. https://doi.org/10.1245/ s10434-006-9058-0. PMID: 17009163.

5. Harter P, Sehouli J, Reuss A, Hasenburg A, Scambia G, Cibula D, Mahner S, Vergote I, Reinthaller A, Burges A, Hanker L, Pölcher M, Kurzeder C, Canzler U, Petry KU, Obermair A, Petru E, Schmalfeldt B, Lorusso D, du Bois A. Prospective validation study of a predictive score for operability of recurrent ovarian cancer: the Multicenter Intergroup Study DESKTOP II. A project of the AGO Kommission OVAR, AGO Study Group, NOGGO, AGO-Austria, and MITO. Int J Gynecol Cancer. 2011;21(2):289-95. https:// doi.org/10.1097/IGC.0b013e31820aaafd. PMID: 21270612.

6. Herzog TJ, Armstrong DK, Brady MF, Coleman RL, Einstein MH, Monk BJ, Mannel RS, Thigpen JT, Umpierre SA, Villella JA, Alvarez RD. Ovarian cancer clinical trial endpoints: Society of Gynecologic Oncology white paper. Gynecol Oncol. 2014;132(1):8-17. https://doi.org/10.1016/j.ygyno. 2013.11.008. Epub 2013 Nov 15. PMID: 24239753; PMCID: PMC4702266.

7. van de Laar R, Kruitwagen RF, Zusterzeel PL, Van Gorp T, Massuger LF. Correspondence: Premature Stop of the SOCceR Trial, a Multicenter Randomized Controlled Trial on Secondary Cytoreductive Surgery: Netherlands Trial Register Number: NTR3337. Int J Gynecol Cancer. 2017;27(1):2. https://doi.org/10.1097/IGC.0000000000000841 PMID: 28002207.

8. Coleman RL, Brady MF, Herzog TJ, Sabbatini P, Armstrong DK, Walker JL, Kim BG, Fujiwara K, Tewari KS, O'Malley DM, Davidson SA, Rubin SC, DiSilvestro P, Basen-Engquist K, Huang H, Chan JK, Spirtos NM, Ashfaq R, Mannel RS. Bevacizumab and paclitaxel-carboplatin chemotherapy and secondary cytoreduction in recurrent, platinum-sensitive ovarian cancer (NRG Oncology/Gynecologic Oncology Group study GOG-0213): a multicentre, open-label, randomised, phase 3 trial. Lancet Oncol. 2017;18(6):779-791. https://doi.org/10.1016/S1470-2045(17)30279-6. Epub 2017 Apr 21. PMID: 28438473; PMCID: PMC5715461.

9. Coleman RL, Spirtos NM, Enserro D, Herzog TJ, Sabbatini P, Armstrong DK, Kim JW, Park SY, Kim BG, Nam JH, Fujiwara K, Walker JL, Casey AC, Alvarez Secord A, Rubin S, Chan JK, DiSilvestro P, Davidson SA, Cohn DE, Tewari KS, Basen-Engquist K, Huang HQ, Brady MF, Mannel RS. Secondary Surgical Cytoreduction for Recurrent Ovarian Cancer. N Engl J Med. 2019;381(20):1929-39. https://doi.org/10.1056/NEJMoa1902626. PMID:31 722153;PMCID:PMC6941470

10. Bois AD, Vergote I, Ferron $\mathrm{G}$, et al. Randomized controlled phase III study evaluating the impact of secondary cytoreductive surgery in recurrent ovarian cancer: AGO DESKTOP III/ENGOT ov20. J Clin Oncol. 2017;35:5501.

11. A du Bois, J Sehouli, I Vergote, et al. Randomized phase III study to evaluate the impact of secondary cytoreductive surgery in recurrent ovarian cancer: final analysis of AGO DESKTOP III/ENGOT-ov20 Proc Am Soc Clin Oncol, 38 (suppl) (2020), Article 6000

12. Shi T, Zhu J, Feng Y, Tu D, Zhang Y, Zhang P, Jia H, Huang X, Cai Y, Yin S, Jiang R, Tian W, Gao W, Liu J, Yang H, Cheng X, Zang R. Secondary cytoreduction followed by chemotherapy versus chemotherapy alone in platinum-sensitive relapsed ovarian cancer (SOC-1): a multicentre, open-label, randomised, phase 3 trial. Lancet Oncol. 2021;22(4):439-49. https://doi.org/10.1016/S1470-2045(21)00006-1 Epub 2021 Mar 8 PMID: 33705695.

13. Marchetti C, Fagotti A, Tombolini V, Scambia G, De Felice F. The Role of Secondary Cytoreductive Surgery in Recurrent Ovarian Cancer: A Systematic Review and Meta-Analysis. Ann Surg Oncol. 2020. https://doi.org/10. 1245/s10434-020-09226-7. Epub ahead of print. PMID: 33067742.

14. Sugarbaker PH. Peritonectomy procedures. Cancer Treat Res. 2007;134:247-64. https://doi.org/10.1007/978-0-387-48993-3_15 PMID: 17633058.

15. Higgins JP, Thompson SG, Deeks JJ, Altman DG. Measuring inconsistency in meta-analyses. BMJ. 2003;327(7414):557-60. https://doi.org/10.1136/ bmj.327.7414.557 PMID:12958120;PMCID:PMC192859.

16. Eisenkop SM, Friedman RL, Spirtos NM. The role of secondary cytoreductive surgery in the treatment of patients with recurrent epithelial ovarian carcinoma. Cancer. 2000;88(1):144-53. https://doi.org/10.1002/(sici)10970142(20000101)88:1\%3c144::aid-cncr20\%3e3.3.co;2-o PMID: 10618617.

17. Zang RY, Zhang ZY, Li ZT, Chen J, Tang MQ, Liu Q, Cai SM. Effect of cytoreductive surgery on survival of patients with recurrent epithelial ovarian 
cancer. J Surg Oncol. 2000;75(1):24-30. https://doi.org/10.1002/10969098(200009)75:1<24:.:aid-jso5>3.0.co;2-I PMID: 11025458.

18. Scarabelli C, Gallo A, Carbone A. Secondary cytoreductive surgery for patients with recurrent epithelial ovarian carcinoma. Gynecol Oncol. 2001;83(3):504-12. https://doi.org/10.1006/gyno.2001.6404 PMID: 11733963.

19. Gronlund B, Lundvall L, Christensen IJ, Knudsen JB, Høgdall C. Surgical cytoreduction in recurrent ovarian carcinoma in patients with complete response to paclitaxel-platinum. Eur J Surg Oncol. 2005;31(1):6773. https://doi.org/10.1016/j.ejso.2004.08.016 PMID: 15642428.

20. Ayhan A, Gultekin M, Taskiran C, Aksan G, Celik NY, Dursun P, Salman MC, Yuce K, Kucukali T. The role of secondary cytoreduction in the treatment of ovarian cancer: Hacettepe University experience. Am J Obstet Gynecol. 2006;194(1):49-56. https://doi.org/10.1016/j.ajog.2005. 06.048 PMID: 16389009

21. Cheng X, Jiang R, Li ZT, Tang J, Cai SM, Zhang ZY, Tian WJ, Zang RY. The role of secondary cytoreductive surgery for recurrent mucinous epithelial ovarian cancer (mEOC). Eur J Surg Oncol. 2009;35(10):1105-8, https://doi.org/10.1016/j.ejso.2009.03.010 Epub 2009 May 13 PMID: 19443175.

22. Rema PN, Suchetha S, Mathew AP, Mathew A, Sebastian P. Secondary cytoreduction in epithelial ovarian cancer recurrence: a perspective from a regional cancer center in India. J Reprod Med. 2009;54(8):50610 PMID: 19769197.

23. Schorge JO, Wingo SN, Bhore R, Heffernan TP, Lea JS. Secondary cytoreductive surgery for recurrent platinum-sensitive ovarian cancer. Int J Gynaecol Obstet. 2010;108(2):123-7. https://doi.org/10.1016/j.ijgo. 2009.08.034 Epub 2009 Nov 4 PMID: 19892337.

24. Goto T, Takano M, Watanabe A, Miyamoto M, Kato M, Hirata J, Sasa H, Furuya K. Potential survival benefit of secondary cytoreductive surgery for recurrent epithelial ovarian, tubal, and peritoneal cancers. Int J Gynecol Cancer. 2011;21(2):263-8. https://doi.org/10.1097/IGC.0b013 e3182098002 PMID: 21270609.

25. Nasu K, Kai K, Hirakawa T, Nishida M, Matsumoto H, Kawano Y, Narahara $\mathrm{H}$. Retrospective analysis of outcomes of secondary debulking surgery for recurrent epithelial ovarian cancer with favorable prognostic factors. J Obstet Gynaecol Res. 2014;40(3):791-6. https://doi.org/10.1111/ jog.12222 Epub 2013 Nov 18 PMID: 24245582.

26. Fan XM, Zhang J, Niu SH, Li KX, Song CZ. Secondary cytoreductive surgery in recurrent epithelial ovarian cancer: A prognostic analysis with 103 cases. Int J Surg. 2017;38:61-6. https://doi.org/10.1016/j.ijsu. 2016.12.031 Epub 2016 Dec 24 PMID: 28027999.

27. Chi DS, McCaughty K, Diaz JP, Huh J, Schwabenbauer S, Hummer AJ, Venkatraman ES, Aghajanian C, Sonoda Y, Abu-Rustum NR, Barakat RR. Guidelines and selection criteria for secondary cytoreductive surgery in patients with recurrent, platinum-sensitive epithelial ovarian carcinoma. Cancer. 2006;106(9):1933-9. https://doi.org/10.1002/cncr.21845 PMID: 16572412.

28. Salani R, Santillan A, Zahurak ML, Giuntoli RL 2nd, Gardner GJ, Armstrong DK, Bristow RE. Secondary cytoreductive surgery for localized, recurrent epithelial ovarian cancer: analysis of prognostic factors and survival outcome. Cancer. 2007;109(4):685-91. https://doi.org/10.1002/ cncr.22447 PMID: 17219441.

29. Tian WJ, Jiang R, Cheng X, Tang J, Xing Y, Zang RY. Surgery in recurrent epithelial ovarian cancer: benefits on Survival for patients with residual disease of $0.1-1 \mathrm{~cm}$ after secondary cytoreduction. J Surg Oncol. 2010;101(3):244-50. https://doi.org/10.1002/jso.21491. PMID: 20112269.

30. Kumar S, Srinivasan A, Phillips A, Madhupriya R, Pascoe J, Nevin J, Elattar A, Balega J, Cummins C, Sundar S, Kehoe ST, Singh K. Does sites of recurrence impact survival in secondary cytoreduction surgery for recurrent epithelial ovarian cancer? J Obstet Gynaecol. 2020;40(6):84955. https://doi.org/10.1080/01443615.2019.1674264 Epub 2020 Jan 14 PMID: 31933417

31. van de Laar R, Kruitwagen RF, IntHout J, Zusterzeel PL, Van Gorp T, Massuger LF. Surgery for Recurrent Epithelial Ovarian Cancer in the Netherlands: A Population-Based Cohort Study. Int J Gynecol Cancer. 2016;26(2):268-75. https://doi.org/10.1097/IGC.00000000000000598 PMID: 26588237.
32. Bickell NA, Egorova N, Prasad-Hayes M, Franco R, Howell EA, Wisnivesky J, Deb P. Secondary Surgery Versus Chemotherapy for Recurrent Ovarian Cancer. Am J Clin Oncol. 2018;41(5):458-64. https://doi.org/10. 1097/COC.0000000000000310 PMID:27391357;PMCID:PMC5665721.

33. Chuang CM, Chou YJ, Yen MS, Chao KC, Twu NF, Wu HH, Wen KC, Chen YJ, Wang PH, Lai CR, Chou P. The role of secondary cytoreductive surgery in patients with recurrent epithelial ovarian, tubal, and peritoneal cancers: a comparative effectiveness analysis. Oncologist. 2012;17(6):847-55. https://doi.org/10.1634/theoncologist.2011-0373. Epub 2012 May 16. PMID: 22591974; PMCID: PMC3380884.

34. Matsumoto A, Higuchi T, Yura S, Mandai M, Kariya M, Takakura K, Fujii S. Role of salvage cytoreductive surgery in the treatment of patients with recurrent ovarian cancer after platinum-based chemotherapy. J Obstet Gynaecol Res. 2006;32(6):580-7. https://doi.org/10.1111/j.1447-0756. 2006.00460.x PMID: 17100820.

35. van de Laar R, Zusterzeel PL, Van Gorp T, Buist MR, van Driel WJ, Gaarenstroom KN, Arts HJ, van Huisseling JC, Hermans RH, Pijnenborg JM, Schutter EM, Pelikan HM, Vollebergh JH, Engelen MJ, Inthout J, Kruitwagen RF, Massuger LF. Cytoreductive surgery followed by chemotherapy versus chemotherapy alone for recurrent platinum-sensitive epithelial ovarian cancer (SOCceR trial): a multicenter randomised controlled study. BMC Cancer. 2014;14:22. https://doi.org/10.1186/1471-2407-1422 PMID:24422892;PMCID:PMC3897943.

36. Gockley A, Melamed A, Cronin A, Bookman MA, Burger RA, Cristae MC, Griggs JJ, Mantia-Smaldone G, Matulonis UA, Meyer LA, Niland J, O'Malley DM, Wright AA. Outcomes of secondary cytoreductive surgery for patients with platinum-sensitive recurrent ovarian cancer. Am J Obstet Gynecol. 2019;221(6):625.e1-625.e14. https://doi.org/10. 1016/j.ajog.2019.06.009 Epub 2019 Jun 14 PMID: 31207237.

37. Felsinger M, Minar L, Weinberger V, Rovny I, Zlamal F, Bienertova-Vasku J. Secondary cytoreductive surgery - viable treatment option in the management of platinum-sensitive recurrent ovarian cancer. Eur J Obstet Gynecol Reprod Biol. 2018;228:154-60. https://doi.org/10. 1016/j.ejogrb.2018.06.036 Epub 2018 Jun 20 PMID: 29957400.

38. Szczesny W, Langseth H, Myklebust TÅ, Kaern J, Tropé C, Paulsen T. Survival after secondary cytoreductive surgery and chemotherapy compared with chemotherapy alone for first recurrence in patients with platinum-sensitive epithelial ovarian cancer and no residuals after primary treatment. A registry-based study. Acta Obstet Gynecol Scand. 2018;97(8):956-965. https://doi.org/10.1111/aogs.13361. Epub 2018 May 22. PMID: 29790149.

39. Lee CK, Lord S, Grunewald T, Gebski V, Hardy-Bessard AC, Sehouli J, Woie K, Heywood M, Schauer C, Vergote I, Scambia G, Ferrero A, Harter P, Pujade-Lauraine E, Friedlander M. Impact of secondary cytoreductive surgery on survival in patients with platinum sensitive recurrent ovarian cancer: analysis of the CALYPSO trial. Gynecol Oncol. 2015;136(1):18-24. https://doi.org/10.1016/j.ygyno.2014.09.017 Epub 2014 Oct 2 PMID: 25281492.

40. Silvia Ortega, José Angel Mínguez, José Manuel Aramendía, Marta Santisteban, Fernando Martinez-Regueira, Pablo Martí-Cruchaga, Juan Luis Alcázar, Matías Jurado. The impact of secondary cytoreductive surgery on survival in first recurrence of platinum sensitive epithelial ovarian cancer. Eur J Gynaecol Oncol. 2020, 41(4): 523-530.

41. So M, Miyamoto T, Murakami R, Abiko K, Hamanishi J, Baba T, Mandai $M$. The efficacy of secondary cytoreductive surgery for recurrent ovarian, tubal, or peritoneal cancer in Tian-model low-risk patients. J Gynecol Oncol. 2019;30(6): e100. https://doi.org/10.3802/jgo.2019.30. e100 PMID:31576692;PMCID:PMC6779625.

42. Güngör M, Ortaç F, Arvas M, Kösebay D, Sönmezer M, Köse K. The role of secondary cytoreductive surgery for recurrent ovarian cancer. Gynecol Oncol. 2005;97(1):74-9. https://doi.org/10.1016/j.ygyno.2004. 11.057 PMID: 15790440.

43. Oksefjell H, Sandstad B, Tropé C. The role of secondary cytoreduction in the management of the first relapse in epithelial ovarian cancer. Ann Oncol. 2009;20(2):286-93. https://doi.org/10.1093/annonc/mdn591 Epub 2008 Aug 25 PMID: 18725390.

44. Takahashi A, Kato K, Matsuura M, Katsuda T, Matoda M, Nomura H, Okamoto S, Kanao H, Kondo E, Omatsu K, Utsugi K, Takeshima N. Comparison of secondary cytoreductive surgery plus chemotherapy with 
chemotherapy alone for recurrent epithelial ovarian, tubal, or peritoneal carcinoma: A propensity score-matched analysis of 112 consecutive patients. Medicine (Baltimore). 2017;96(37): e8006. https://doi.org/ 10.1097/MD.0000000000008006 PMID:28906381;PMCID:PMC5604650.

45. Kajiyama H, Suzuki S, Yoshikawa N, Kawai M, Shibata K, Nagasaka T, Kikkawa F. Oncologic outcomes after secondary surgery in recurrent clear-cell carcinoma of the ovary. Int J Gynecol Cancer. 2019;29(5):9105. https://doi.org/10.1136/ijgc-2018-000142 Epub 2019 Mar 5 PMID: 30839284.

\section{Publisher's Note}

Springer Nature remains neutral with regard to jurisdictional claims in published maps and institutional affiliations.

- fast, convenient online submission

- thorough peer review by experienced researchers in your field

- rapid publication on acceptance

- support for research data, including large and complex data types

- gold Open Access which fosters wider collaboration and increased citations

- maximum visibility for your research: over $100 \mathrm{M}$ website views per year

At BMC, research is always in progress.

Learn more biomedcentral.com/submissions 